\title{
HUBUNGAN PIJAT BAYI DENGAN KENAIKAN BERAT BADAN PADA BAYI USIA 1 - 6 BULAN DI RIU MOM KIDS AND BABY SPA DI SUKOHARJO PATI
}

\author{
Nopri Padma Nudesti, S.S.T.,M.Kes ${ }^{1)}$, Heni Setiyowati ${ }^{2)}$ \\ ${ }^{1}$ Prodi Diploma III Kebidanan, STIKes Bakti Utama Pati \\ ${ }^{2}$ Prodi Diploma III Kebidanan, STIKes Bakti Utama Pati \\ Email: nopri@stikesbup.ac.id
}

\begin{abstract}
ABSTRAK
Pijat bayi adalah kegiatan memberikan stimulasi atau urutan kepada bayi dengan sentuhan, gerak, ditambahi dengan stimulasi pendengaran dan juga stimulasi visual yang dapat meningkatkan berat badan bayi. Tujuan penelitian ini adalah untuk mengetahui hubungan pijat bayi dengan kenaikan berat badan bayi pada bayi usia 1-6 bulan di Riu Mom Kids And Baby SPA di Sukoharjo Pati. Jenis penelitian ini adalah survey analitik dan menggunakn metode cross sectional. Tekhnik sampling yang digunakan dalam penelitian ini adalah total sampling. Hasil penelitian menunjukan adanya hubungan pijat bayi dengan kenaikan berat badan pada bayi usia 1-6 bulan di Riu Mom Kids And Baby SPA di Sukoharjo Pati dengan nilai $p$ value 0,019 < 0,05. Kesimpulan penelitian adalah ada hubungan pijat bayi dengan kenaikan berat badan pada bayi usia 1-6 bulan di Riu Mom Kids And Baby SPA di Sukoharjo Pati.
\end{abstract}

Kata Kunci: pijat bayi, kenaikan berat badan bayi

\begin{abstract}
Baby massage is an activity toprovide stimulation or sequence to the baby with touch, motion coupled with auditory stimulation and visual stimulation which can increase the baby's weight. The purpose of this research is to determine the relationship of baby massage with baby weight gain in infants aged 1-6 month at Riu Mom Kids And Baby SPA in Sukoharjo Pati. This type of research is an survey analitik and uses a cross sectional method. The sampling technique used total sampling. Research results show the relationship of baby massage with baby weight gain in infants aged 1-6 month at Riu Mom Kids And Baby SPA in Sukoharjo Pati with p value $0,019<0,05$. The conclusion of this research means that there is a relationship of baby massage with baby weight gain in infants aged 1-6 month at Riu Mom Kids And Baby SPA in Sukoharjo Pati.
\end{abstract}

Keywords: Baby massage, baby weight gain in infants

\section{PENDAHULUAN}

Bayi merupakan makhluk yang perlu dilindungi. Semua kebutuhannya harus dipenuhi seperti yang diinginkanya, tetapi ia belum pandai menyatakan keinginan itu. Mendengar bayinya menangis, ibu yang pertama kali mempunyai bayi itu tentu merasa bingung tidak mengerti apa yang harus diperbuatnya.

Masa bayi adalah suatu masa yang penting dalam perkembangan manusia. Setiap orang akan mempunyai laju perkembanganya sendiri, namun dalam garis besarnya terdapat persamaanpersamaan sehingga proses pertumbuhan dan perkembangan dapat dikelompokan ke dalam beberapa masa. Para ahli perkembangan memberikan batasanusia 18-24 bulan bagi masa bayi, dimana terjadi perubahan-perubahan yang cepat dan khas sifatnya. Lagi pula sejak usia 2 tahun seorang anak sudah mulai menunjukan fungsi kognitif yang memadai sehingga mussen (1979) berpendapat bahwa dengan masa bayi selesai dan mulailah masa kanak-kanak (Machmud, 2010).

Pertumbuhan dan perkembangan bayi meliputi berat badan, organ tubuh, gigi, peningkatan masa tulang, dan peningkatan jaringanan otot.Berat badan merupakan tolak ukur untuk menentukan kesehatan seorang anak (widyastuti, 2008). 
Sentuhan (pijat) yang diberikan kepada bayi setelah kelahiran memiliki manfaat yang besar pada pertumbuhan dan perkembangan bayi. Secara ilmiah, pijatan memberikan stimulus pada hormone di dalam tubuh, seperti nafsu makan, tidur, ingatan, pengaturan temperature, mood, perilaku, fungsi pembuluh darah, kontraksi otot, pengaruh sistem endokrin dan depresi. Penelitian lain menunjukan hasil pijat bayi dapat meningkatkan berat badan bayi (Prasetyono, 2009).

Pijat bayi beberapa waktu ini digemari karena bisa membuat bayi lebih sehat dan tidak rewel.Pijat bayi juga bisa membuat otot bayi lebih kuat, imunitasnya meningkat, menaikan berat badan bayi, mengurangi rasa sakit, dan membuat tidur lebih lelap.Pijat bayi bisa merangsang otot motorik, memperbaiki kekebalannya serta menambah jumlah produksi darah putih yang menjadi lebih sehat.Dengan memberikan pijatan pada tubuh si bayi nantinya membuat tubuh bayi mengalami penurunan hormone kortisol, yaiu hormone penyebab stress. Hasilnya bayi menjadi lebih riang dan tidak suka menangis. Jika bayi mengalami masalah berat badan, memijat secara teratur juga memberikan manfaat untuk mempengaruhi rangsangan syaraf dan kulit dan memproduksi hormone-hormon berpengaruh dalam menaikan berat badan (Roesli, 2013).

Menurut penelitian oleh Alfiani Kosyda (2010) dengan judul "Pengaruh Pijat Bayi Dengan Kenaikan Berat Badan Pada Bayi Umur 0-3 bulan di BPS Saraswati" menunjukanterdapat pengaruh pijat bayi terhadap kenaikan berat badan bayi umur 0-3 bulan di BPS Saraswati. Perbedaan peningkatan berat badan diuji dengan paired sample t-test pada tingkat kepercayaan 95\%. Hasil uji normalitas data adalah pada kelompok eksperimen maupun kelompok kontrol nilai signifikan didapatkan $(\mathrm{p})>0,05$ maka data pada kelompok control berdistribusi normal. Adanya peningkatan berat badan yang signifikan disebabkan oleh adanya perangsangan nervus vagus yang kemudian meningkatkan kadar enzim penyerapan gastrin dan insulin.

Berdasarkan survey awal penelitian yang dilakukan di Riu Mom Kids And Baby SPA di Sukoharjo Pati pada 10 ibu yang mempunyai bayi usia 1-6 bulan, terdapat 7 bayi yang rutin mengikuti pijat bayi mengalami kenaikan berat badan baik, sedanglkan 3 bayi yang tidak melakukan pijat bayi dengan rutin mengalami kenaikan berat badan yang kurang.

Tujuan dilakukannya penelitian ini adalah untuk mengetahui hubungan pijat bayi dengan kenaikan berat badan pada bayi usia 1-6 bulan di Riu Mom Kids and Baby SPA di Sukoharjo Pati.

Berdasarkan uraian diatas perumusan masalah dalam penelitian ini adalah "Adakah Hubungan Pijat Bayi Dengan Kenaikan Berat Badan Pada Bayi Usia 1-6 Bulan di Riu Mom Kids and Baby SPA di Sukoharjo Pati

\section{METODE}

Jenis penelitian yang digunakan bersifat survey analitik. Metode penelitian yang digunakan dalam penelitian ini adalah cross sectional yaitu dimana obyek penelitian ada beberapa populasi yang diamati pada waktu yang sama. Penentuan sampel menggunakan total sampling, seluruh populasi dijadikan sampel penelitian. Untuk menguji hubungan antara dua variabel dalam penelitian ini maka analisa statistik yang digunakan dalam penelitian ini adalah Chi Square.

Dalam penelitian ini yang menjadi variabel independen adalah pijat bayi (X). Variabel dependen dalam penelitian ini adalah kenaikan berat badan (Y).

Populasi pada penelitian ini adalah ibu yang mengalami nyeri pada punggung sebanyak 35 responden. 


\section{HASIL}

a. Pijat Bayi

1. Analisis Univariat

Tabel 4.1 Distribusi Frekuensi Pijat Bayi 1-6 Bulan Di Riu Mom Kids And Baby SPA Di Sukoharjo Pati

\begin{tabular}{lccc}
\hline No & Pijat Bayi & Frekuensi & Presentase(\%) \\
\hline 1. & Tidak & 9 & 25,7 \\
2. & Rutin & 26 & 74,3 \\
\hline & Total & 35 & 100
\end{tabular}

\section{Sumber: Data Primer 2020}

Berdasarkan tabel 4.1 diketahui bahwa responden yang melakukan pijat bayi secara rutin sebanyak 26 bayi $(74,3 \%)$,

dan bayi yang melakukan pijat bayi tidak rutin sebanyak 9 bayi $(25,7 \%)$.

Tabel 4.2 Distribusi Frekuensi Kenaikan Berat Badan Bayi1-6 Bulan Di Riu Mom Kids And Baby SPA Di Sukoharjo Pati

\begin{tabular}{llll}
\hline No & Kenaikan BB & Frekuensi & Presentase (\%) \\
\hline 1. & Lebih & 4 & 11,4 \\
2. & Normal & 23 & 65,7 \\
3. & Kurang & 8 & 22,9 \\
\hline Total & & 35 & 100
\end{tabular}

Sumber : Data Primer 2020

Berdasarkan tabel 4.4 diketahui bahwa responden yang memiliki kenaikan berat badan normal sebanyak 23 bayi $(65,7 \%)$, kemudian yang memiliki kenaikan berat badan lebih sebanyak 4 bayi $(11,4 \%)$, dan yang memiliki kenaikan berat badan kurang sebanyak 8 bayi $(22,9 \%)$.

c. Karateristik responden berdasarkan usia

Tabel 4.3 Distribusi Frekuensi Usia Bayi 1-6 Bulan Di Riu Mom Kids And Baby SPA Di Sukoharjo Pati

\begin{tabular}{cccc}
\hline No & Usia & Frekuensi & Presentase (\%) \\
\hline 1. & 1-2 Bulan & 5 & $14 ., 3$ \\
2. & 3-4 Bulan & 11 & 31,4 \\
3. & $5-6$ Bulan & 19 & 54,3 \\
\hline & Total & 35 & 100
\end{tabular}

Sumber: Data Primer 2020

Berdasarkan tabel 4.3 diketahui bahwa responden yang berusia 1-2 bulan ada 5 bayi (14,3\%), berusia 3-4 bulan ada
11 bayi $(31,4 \%)$ dan bayi yang berusia 5-6 bulan ada 19 bayi $(54,3 \%)$.

d. Karakteristik responden berdasarkan jenis kelamin 
Tabel 4.4Distribusi Frekuensi Jenis Kelamin Bayi 1-6 Bulan Di Riu Mom Kids And Baby SPA Di Sukoharjo Pati

\begin{tabular}{llll}
\hline No & Jenis Kelamin & Frekuensi & Presentase (\%) \\
\hline 1. & Laki-laki & 11 & 31,4 \\
2. & Perempuan & 24 & 68,6 \\
\hline Total & & 35 & 100 \\
\hline
\end{tabular}

Sumber: Data Primer 2020

Berdasarkan tabel 4.2 diketahui bahwa responden dengan jenis kelamin perempuan

dengan jumlah 24 bayi $(68,6 \%)$, dan bayi laki-laki sebanyak 11 bayi $(31,4 \%)$.

2. Analisis Bivariat

Tabel 4.5 Tabulasi Silang Hubungan Pijat Bayi dengan Kenaikan Berat Badan Pada Bayi Usia 1-6 Bulan Di Riu Mom Kids And Baby SPA Di Sukoharjo Pati

\begin{tabular}{|c|c|c|c|c|c|c|c|c|c|c|}
\hline \multirow{3}{*}{$\begin{array}{l}\mathbf{N} \\
\mathbf{0}\end{array}$} & \multirow{3}{*}{$\begin{array}{l}\text { Pija } \\
\text { t } \\
\text { Bayi }\end{array}$} & \multicolumn{6}{|c|}{ Kenaikan BB } & \multirow{2}{*}{ Total } & \multirow{2}{*}{ P yálue } & \multirow{2}{*}{$\chi^{2}$} \\
\hline & & \multicolumn{2}{|c|}{ Lebih } & \multicolumn{2}{|c|}{ Normal } & \multicolumn{2}{|c|}{ Kurang } & & & \\
\hline & & $F$ & $\%$ & $\mathrm{~F}$ & $\%$ & $\mathrm{~F} \%$ & 7 & $\%$ & 0,019 & 7,886 \\
\hline 1. & $\begin{array}{l}\text { Pijat } \\
\text { tidak } \\
\text { rutin }\end{array}$ & 0 & 0 & 4 & 11,4 & 514,3 & 9 & 25,7 & & \\
\hline 2. & $\begin{array}{l}\text { Pijat } \\
\text { rutin }\end{array}$ & 4 & 11,4 & $\begin{array}{l}1 \\
9 \\
\end{array}$ & 54,3 & 38,6 & 5 & 74,3 & & \\
\hline To & & 4 & 11,4 & $\begin{array}{l}2 \\
3\end{array}$ & 65,7 & $8 \quad 22,9$ & 35 & 100 & & \\
\hline
\end{tabular}

Sumber: Data Primer 2020

Berdasarkan tabel 4.5 diperoleh hasil bahwa dari 35 responden di Riu Mom Kids And Baby SPA di Sukoharjo Pati dengan yang melakukan pijat bayi secara rutin dengan kenaikan berat badan lebih ada 4 bayi $(11,4 \%)$, melakukan pijat bayi secara rutin dengan kenaikan berat badan normal ada 19 bayi $(54,3 \%)$ dan yang melakukan pijat bayi secara rutin dengan kenaikan berat badan kurang ada 8 bayi $(8,6 \%)$. Sedangkan yang melakukan pijat secara tidak rutin dengan kenaikan berat badan normal sebanyak 4 bayi $(11,4 \%)$ dan yang memiliki kenaikan berat badan kurang 5 $(14,3 \%)$.

Hasil uji hubungan dengan chi square di dapatkan hasil nilai chi square hitung 7,886 dan p value $0,019<0,05$ artinya Ha diterima dan Ho ditolak, berarti ada hubungan antara pijat bayi dengan kenaikan berat badan pada bayi usia 1-6 bulan di Riu Mom Kids and Baby SPA di SukoharjoPati.

\section{PEMBAHASAN}

\section{Analisis Univariat}

a. Distribusi Frekuensi Pijat Bayi 1-6 Bulan Di Riu Mom Kids And Baby Spa Di Sukoharjo Pati
Berdasarkan hasil penelitian diketahui bahwa sebagian besar bayi yang pijat di riu mom kids and baby spa di sukoharjo pati melakukan pijat rutin 26 bayi $(74,3 \%)$ dan bayi yang melakukan pijat tidak rutin sebanyak 9 bayi $(25,7 \%)$.

Pijat bayi adalah kegiatan memberikan stimulasi atau urutan kepada bayi dengan sentuhan, gerak, ditambahi dengan stimulasi pendengaran dan juga viual (Doska, 2019).

Menurut Santi (2012), ada beberapa mekanisme yang dapat menerangkan mekanisme dasar pijat bayi, antara lain pengeluaran beta endorphin, aktifitas nervus vagus, produksi serotonin dan mengubah gelombanh otak.

Penelitian ini sesuai dengan teori yang dikemukakan oleh Roseli (2013) yang mengatakan salah satu manfaat pijat bayi adalah untuk meningkatkan berat badan bayi dan pijat bayidapat menimbulkan efek biokimia dan fisik positif. Pijat bayi menyebabkan peningkatan aktivitas nervus vagus dan akan merangsang hormone pencernaan antara lain insulin gastrin. 
b. Distribusi Frekuensi Kenaikan Berat Badan Bayi1-6 Bulan Di Riu Mom Kids And Baby SPA Di Sukoharjo Pati

Berdasarkan hasil penelitian diketahui bahwa sebagian besar bayi yang pijat di Riu Mom Kids and Baby SPA di Sukoharjo Pati yang memiliki kenaikan berat badan lebih sebanyak 4 bayi $(11,4 \%)$, yang memiliki kenaikan berat badan normal sebanyak 23 bayi $(65,7 \%)$ dan yang memiliki kenaikan berat badan kurang sebanyak 8 bayi $(22,9 \%)$.

Menurut Soetijiningsih, pertumbuhan (growth) berkaitan dengan masalah perubahan dalam besar jumlah, ukuran atau dmensi tingkat sel, organ maupun individu, yang bisa diukur dengan ukuran berat (gram, pound, kilogram) dan ukuran panjang $(\mathrm{cm}$, meter).

Hasil penelitian ini sejalan dengan penelitian yang dilakukan oleh Rosyiada, (2010) tentang "pengaruh pijat bayi dengan kenaikan berat badan pada bayi 03 bulan di BPS Saraswati Sleman Yogyakarta" dengan hasil penelitian ada hubungan antara pijat bayi dengan kenaikan berat badan pada bayi 0-3 bulan di BPS Saraswati Sleman Yogyakarta, ditandai dengan $\mathrm{p}$ value $<0,005$.

\section{Analisis Bivariat}

a.Hubungan Pijat Bayi dengan Kenaikan Berat Badan Pada Bayi Usia 1-6 Bulan Di Riu Mom Kids And Baby SPA Di Sukoharjo Pati

Berdasarkan hasil korelasi hubungan pijat bayi dengan kenaikan berat badan dari tabel 4.5 menjelaskan bahwa dari 35 responden di Riu Mom Kids And Baby SPA di Sukoharjo Pati dengan yang melakukan pijat tidak rutin sebanyak 9 bayi $(25,7 \%)$. Kemudian yang memiliki kenaikan berat badan normal sebanyak 4 bayi (11,4\%) dan yang memiliki kenaikan berat badan kurang $5(14,3 \%)$. Sedangkan yang melakukan pijat bayi rutin sebanyak 26 bayi (74,3\%). Kemudian yang memiliki kenaikan berat badan lebih sebanyak 4 bayi $(11,4 \%)$, yang memiliki kenaikan berat badan normal sebanyak 19 bayi (54,3\%) dan bayi yang memiliki kenaikan berat badan kurang sebanyak 8 bayi $(8,6 \%)$. Dengan hasil analisis chi square di dapatkan hasil nilai chi square hitung 7,886 dan $p$ value $0,019<0,05$ artinya Ha diterima dan Ho ditolak, berarti ada hubungan antara pijat bayi dengan kenaikan berat badan pada bayi usia 1-6 bulan di Riu Mom Kids and Baby SPA di Sukoharjo Pati.

Pijatan adalah sentuhan dengan kesadaran pada bayi untuk mendorong pertumbuhan dan memainkan peranan penting bagi perkembangan fisik dan mental bayi karena sistem sirkulasi dan kekebalan tubuh dari bayi akan membaik. Pijatan merupakan tehnik penyembuhan yang mempengaruhi keadaan fisik, emosional dan spiritual anak.

Hasil penelitian ini sejalan dengan Prof.T.Field \& Scafidi cit Dasuki (2010) menunjuka bhawa 20 bayi prematur yang dipijat selama 10 enit, terjadi kenaikan berat badan $20 \%$ - $47 \%$ perhari lebih dari yang tidak dipijat.

\section{SIMPULAN DAN SARAN Simpulan}

1. Pijat Bayi di Riu Mom Kids And Baby SPA di Sukoharjo Pati melakukan pijat secara rutin sebanyak 26 bayi $(74,3 \%)$

2. Kenaikan berat badan di Riu Mom Kids And Baby SPA di Sukoharjo Pati yang terbanyak memiliki kenaikan berat badan normal sebanyak 23 bayi $(65,7 \%)$

3. Pijat bayi terbanyak pada bayi usia 5-6 $(64,3 \%)$, dengan jenis kelamin terbanyak perempuan 24 bayi $(68,6 \%)$

4. Ada hubungan anatar pijat bayi dengan kenaikan berat badan pada bayi usia 1-6 bulan di Riu Mom Kids and Baby SPA di Sukoharjo Pati dengan hasil nilai chi square hitung 7,886 dan $\mathrm{p}$ value $0,019<$ 0,05 .

\section{Saran}

1. Bagi Orang Tua Bayi

Sebaiknya ibu melakukan pijat bayi rutin pada usia 1-6 bulan, dimana usia tersebut adalah fase dimana kenaikan berat badan harus diperhatikan supaya tetap terjadi kenaikan berat badan yang baik.

2. Bagi Mahasiswa

Perlunya peningkatan lebih lanjut terhadap beberapa kajian baik secara riset maupun teori yang dapat menambah wawasan peneliti untuk dijadikan bekal 
dalam melayani masyarakat, dan juga bagi diri peneliti sendiri.

3. Bagi Tenaga Kesehatan

Perlu perhatian khusus dari tenaga kesehatan untuk mengembangkan ilmu pengtahuannya terutama tentang pijat bayi dengan kenaikan berat badan. Sehingga bisa memberikan informasi kepada kepada masyarakat bahwa pijat bayi mempunyai banyak manfaat.

4. Bagi Peneliti Selanjutnya

a. Dalam penelitian ini literature yang membahas tentang pijat bayi dengan kenaikan berat badan, sebaiknya lebih banyak literature terbaru yang digunakan sehingga informasi yang diperoleh dapat lebih maksimal.

b. Diharapkan melakukan penelitian lebih lanjut lebih memperhatikan faktor lain penyebab kenaikan berat badan selain dilihat dari satu faktor yaitu pijat bayi.

5. Bagi Institusi

Diharapkan dapat menyediakan lebih banyak lagi buku referensi tentang pijat bayi yang berhubungan dengan kenaikan berat badan sehingga mahasiswa dapat mendapatkan referensi yang akurat dan mudah dalam mendapatkan informasi.

\section{DAFTAR PUSTAKA}

Arisma. 2009. Gizi Dalam Daur Ulang.Jakarta : EGC

Dasuki. 2010. Pengaruh Pemijatan Terhadap Kenaikan Berat Badan Dan Lama Tidur Bayi Usia 1-3 Bulan. Jurnal Penelitian Kesehatan Suara For Ikes Vol. 2.

Depkes RI. 2009. Pedoman Penggunaan Kartu Menuju Sehat (KMS) Balita. Jakarta.

Dewi. 2012. Bahan Pangan, Gizi, dan Kesehatan. Bandung : Alfabeta.

Dintansari, Esa. 2010. Studi Komparatif Penambahan Berat Badan Bayi Umur 0-

6 Bulan Yang Diberi MP-ASI. Bidan Prada : Jurnal Ilmiah Kebiadanan, Vol. 1 No. 1 Desember 2010. Akademi Kebidanan YLPP Purwokerto.

Fauziah, Afroh. 2018. Pengaruh Pijat Bayi Terhadap Kenaikan Berat Badan Dan Kualitas Tidur Bayi Di Puskesmas Jetis
Yogyakarta. Jurnal Ilmiah Kesehatan Vol. 6 No. 2

Hidayat, A. 2011. Pengantar Ilmu Keperawatan Anak. Jakarta : Salemba Medika.

Hastuti, Puji\& Nopri, 2015. Buku Ajar Asuhan Kebidanan Neonatus, Bayi dan Balita. Yogyakarta : PT Kanisius.

Haryanti, Nina. 2012. Analisis Faktor-Faktor Yang Mempengaruhi Berat Badan Bayi Saat Lahir Di Kota Surakarta. Universitas Sebelas Maret.

Irva, Sasmi. 2014. Pengaruh Terapi Pijat Bayi Terhadap Kenaikan Berat Badan Bayi. JOM PSIK Vol. 1 No. 2 Oktober 2014. Universitas Riu.

Kalsum, Ummi. 2014. Peningkatan Berat Badan Bayi Melalui Pemijatan. Jurnal Keperawatan Vol. 17 No. 1

Kusnadi, Rusmil. 2008. Pertumbuhan dan Perkembangan Anak. http://www . Kelly.mom.com. (13 Desember 2019 : 15.40).

Kristiani, Agustin. 2013. Perbedaan Status Gizi Bayi Umur 0-6 Bulan Yang Mendapatkan ASI Dan Susu Formula Di Salatiga. KTI. Fakultas Ilmu Kesehatan Universitas Muhammadiyah Surakarta.

Mangunkusumo, Cipto. 2008. Penuntun DIIT Anak.Jakarta : PT Gramedia Pustaka Utama.

Notoatmojo, Soekidjo. 2018. Metodologi Penelitian Kesehatan.Jakarta : PT Asdi Mahasatya.

Nursalam, dkk. 2009. Asuhan Keperawatan Bayi dan Anak (Untuk Bidan Dan Perawat). Jakarta : Salemba Medika.

Ramini, Novy. 2019. Pijat Bayi Menaikan Berat Badan Bayi Usia 0-6 Bulan. Jurnal Kesehatan Prima Vol. 13 No. 2

Roesli, utami. 2013. Pedoman Pijat Bayi. Jakarta : PT. Trubus Agriwidya.

Rosalina, Ina. 2015. Fisiologi Pijat Bayi. Bandung : Trikarsa.

Rosyida, Alfiana. 2010. Pengaruh Pijat Bayi Dengan Kenaikan Berat Badan Pada Bayi 0-3 Bulan Di BPS Saraswati Sleman Yogyakarta. KTI. STIKES Jendral Ahmad Yani. 
Sediaoetama, Achamad. 2010. Ilmu Gizi. Jakarta : PT Dian Rakyat.

Sears, Wiliam. 2007. The Baby Book. Jakarta : PT Serambi Ilmu Semesta.

Soetjiningsih. 2012. Tumbuh Kembang Anak. Jakarta : Kedokteran EGC

Sugiyono. 2015. Metode Penelitian Kuantitatif Kualitatif Dan $R \& D$. Bandung: IKAPI.

Triswati, Nia. 2012. Pengaruh Pijat Bayi Teerhadap Kenaikan Berat Badan Pada Bayi Usia 3-4 Bulan Di Wilayah Kerja Puskesmas Kendaton Bandar Lampung. Jurnal Dunia Kesmas Vol. 2 No. 1

Prasetyono. 2013. Buku Pintar Pijat Bayi. Jogjakarta : Buku Biru.
Qoyimah, Uswatun. 2009. Hubungan Antara Pijat Bayi Dengan Kenaikan Berat Badan Bayi Umur 0-3 Bulan Di Pondok Bersalin Desa Balak Siaga Cawas Klaten.Jurnal Ilmiah Kebiadanan, Vol. 1 No. 1.

Yuliana, Lia. 2013. Tingkat Pengetahuan Ibu Tentang Pijat Bayi Di Bps Suratini Soewarno. KTI. STIKES Kusuma Husada.

Widyani Retno dan Widyastuti Danis. 2008. Panduan Perkembangan Anak 0-1 Tahun. Jakarta : Puspa Sudra.

Wong, L. D., Hockenberry. 2009. Buku Ajar Keperawatan Pediatrik. Edisi 6 Vol. 2. Jakarta: EGC 